\title{
A CONTROLLED TRIAL OF MEPROBAMATE IN ANXIOUS OUT-PATIENTS
}

\author{
BY \\ JOHN M. HINTON \\ From the Professorial Unit, Maudsley Hosp tal, London
}

Meprobamate was first synthesized by Ludwig and Piech in 1951. Its pharmacological properties have been studied by Berger, who described it as an interneuronal blocking agent related to mephenesin (Berger, 1954; Berger, Hendley, Ludwig, and Lynes, 1956). He noted that when it was administered to monkeys they became more manageable and did not demonstrate fear when handled. Early reports of its clinical use were favourable, patients experiencing relief from anxiety, tension, and tension headache (Borrus, 1955; Selling, 1955). Some later reports have not shown the same degree of success. West and Fernandes da Fonseca (1956) found a significant degree of improvement in patients receiving meprobamate compared with placebo, whereas Raymond, Lucas, Beesley, O'Connell, and Fraser Roberts (1957) found no significant difference from treatment with placebo. Folkson (1957) found only a small number of patients improved while receiving meprobamate and there was an appreciable incidence of toxic effects. Reports of such toxic effects have become more frequent as the use of this compound has increased (Friedman and Marmelzat, 1956; Council on Drugs of American Medical Association, 1957). The aim of the present study was to determine if meprobamate has a beneficial effect on anxious patients and, if possible, to observe which symptoms improve.

\section{Method}

The design of this trial was similar to that used by Davies and Shepherd (1955) in a trial of reserpine. The patients studied were attending the Out-patient Department for treatment, and their symptoms included anxiety and, in the majority, a feeling of tension. Twenty men and 20 women, who were thought to be suitable for treatment with meprobamate and whose ages were between 18 and 60 , were selected. At the initial interview a record was made of the duration of the present condition, of any previous mental illness, and of previous treatment such as drugs, psychotherapy, or E.C.T. The symptoms of anxiety, feelings of tension, depression, photic or compulsive phenomena, insomnia, anorexia, and somatic pains, including headache, were assessed as severe, moderate, mild, slight, or absent. Also, based on all the information available, the patients were assessed as those liable to retain many symptoms or those liable to become relatively free of symptoms.

The patients received either meprobamate, $400 \mathrm{mg}$. q.d.s., or placebo tablets of identical appearance, q.d.s., throughout the trial period of four weeks. The tablets were dispensed to the individuals in a random order known to the pharmacist. The patients were told that they were to receive these tablets for four weeks to see if it would help them. During the trial they were seen at weekly intervals to note their progress and to give supportive psychotherapy if indicated. Any unwanted side-effects of the medication were recorded but in no case were these serious enough for treatment to be stopped. At the end of the four weeks the change in the patient was assessed. He was required to indicate on a form if he considered himself in general to be much better, better, unchanged, worse, or much worse. The doctor also estimated the general change in the patient and assessed the change in the individual symptoms, i.e., anxiety, depression, as above. Changes in the patients' circumstances or attitude during this period were considered; the changes might be environmental or of a psychotherapeutic nature occurring in the course of the five interviews. Until the end of the whole trial and all the assessments were completed the pharmacist did not inform the doctor which tablets the patients received.

\section{Comparison of Groups}

The original data and assessments of the patients in the meprobamate and placebo groups are shown in Tables I and II.

Inspection of Table I shows that the random allocation of the patients into the two groups fulfilled its purpose in distributing them evenly, according to these criteria. The incidence and the severity of the symptoms (Table II) were not significantly different in the two groups. The method of comparison is described below where the results are considered; it has not only been applied to the whole group of patients shown in Table II, but also to the group of patients who completed the trial.

The assessment of psychotherapeutic or environmental change during the trial showed no significant 
TABLE I

DATA OF THE TWO GROUPS AT START OF TRIAL

\begin{tabular}{|c|c|c|}
\hline & Meprobamate & Placebo \\
\hline
\end{tabular}

TABLE II

SYMPTOM ASSESSMENTS OF THE TWO GROUPS AT START OF TRIAL

\begin{tabular}{|c|c|c|c|c|c|c|}
\hline Symptom & Group & Nil & Slight & Mild & Moderate & Severe \\
\hline $\begin{array}{l}\text { Anxiety } \\
\text { Tension } \\
\text { Depression } \\
\text { Insomnia } \\
\text { Anorexia } \\
\text { Compulsions or phobias } \\
\text { Somatic pains (including headaches) }\end{array}$ & $\begin{array}{l}\text { Meprobamate } \\
\text { Placebo } \\
\text { Meprobamate } \\
\text { Placebo } \\
\text { Meprobamate } \\
\text { Placebo } \\
\text { Meprobamate } \\
\text { Placebo } \\
\text { Meprobamate } \\
\text { Placebo } \\
\text { Meprobamate } \\
\text { Placebo } \\
\text { Meprobamate } \\
\text { Placebo }\end{array}$ & $\begin{array}{r}- \\
1 \\
3 \\
3 \\
3 \\
6 \\
9 \\
11 \\
7 \\
12 \\
6 \\
5\end{array}$ & $\begin{array}{r}2 \\
5 \\
2 \\
8 \\
12 \\
8 \\
4 \\
4 \\
4 \\
2 \\
3 \\
7 \\
10\end{array}$ & $\begin{array}{r}10 \\
11 \\
7 \\
11 \\
8 \\
5 \\
6 \\
7 \\
7 \\
4 \\
10 \\
3 \\
7\end{array}$ & $\begin{array}{r}10 \\
7 \\
8 \\
6 \\
1 \\
3 \\
3 \\
1 \\
1 \\
1 \\
-\end{array}$ & $\begin{array}{l}E \\
E \\
z \\
E \\
z \\
E \\
E \\
-\end{array}$ \\
\hline
\end{tabular}

difference between those receiving meprobamate and those receiving the placebo. To ascertain which patients have gained from psychotherapy during five interviews is a difficult exercise. However, if there was an obvious gain of insight into psychological factors relevant in causing the symptoms, or if there was a rewarding discussion of significant emotional problems, these were accepted. For example, a man, who was unofficially engaged, numbered among his symptoms a fear that he had venereal disease. During the trial period he made the decision that he did not want to get married and told the woman concerned; he then lost this symptom. Using these criteria, three of the "meprobamate group" were scored (these three improved) and five of the placebo group (four of these improved). Environmental changes were scored, e.g., a week's holiday or resignation from a worrying job with a cantankerous employer. Four of the " meprobamate group" had such a change (one improving) and four of the control group (two improving).

\section{Results}

Of the 40 patients studied, four failed to complete the four weeks on the tablets. In three of them, all receiving meprobamate, it was due to admission to hospital either from worsening of their state or because they could no longer be maintained at home. The other patient, owing to an error in administration, only took the placebo for two weeks. The three patients admitted to hospital after periods of four, nine, and 21 days were followed up and the information received indicated that they were not improved while taking meprobamate over this period. The patient taking placebo for two weeks only was normally assessed at the end of this time. Three patients did not attend for one of their weekly visits for various reasons; one could only attend at a late hour and so another doctor saw him for three of his visits, and one patient, because of the severity of his phobia, could not attend on two occasions, but his wife came to report his progress and obtain the tablets. These lastmentioned five patients otherwise conformed with the design of the trial. In determining the results, therefore, the group has been studied as one of 36 completing the trial. If the four not completing the trial were not taken into account, this might, in some instances, favour the results of the "meprobamate group" by the exclusion of three who showed no improvement before leaving the trial. Where relevant the results have been assessed for the whole 40 , employing for these results the state of the patient when he stopped treatment.

It may be seen in Table III that, in general, the 
TABLE III

ASSESSMENT OF CHANGE IN GENERAL STATE OF TWO GROUPS AT END OF TRIAL

\begin{tabular}{|c|c|c|c|c|c|}
\hline General Assessment & Much Better & Better & Unchanged & Worse & Much Worse \\
\hline $\begin{array}{l}\text { By doctor }\left\{\begin{array}{l}\text { Meprobamate } \\
\text { Placebo } \\
\text { Meprobamate } \\
\text { Placebo }\end{array}\right. \\
\text { By patient }\end{array}$ & $\begin{array}{l}4 \\
2 \\
3 \\
4\end{array}$ & $\begin{array}{r}10 \\
9 \\
11 \\
6\end{array}$ & $\begin{array}{l}3 \\
7 \\
2 \\
8\end{array}$ & $\begin{array}{c}-1 \\
1 \\
1\end{array}$ & E \\
\hline
\end{tabular}

TABLE IV

ASSESSMENT OF CHANGE IN SYMPTOMS OF TWO GROUPS AT END OF TRIAL

\begin{tabular}{|c|c|c|c|c|c|c|c|}
\hline Symptom & Group & Much Better & Better & Unchanged & Worse & Much Worse & N.A. \\
\hline $\begin{array}{l}\text { Anxiety } \\
\text { Tension } \\
\text { Depression } \\
\text { Insomnia } \\
\text { Anorexia } \\
\text { Compulsions or phobias } \\
\text { Somatic pains (including headaches) }\end{array}$ & $\begin{array}{l}\text { Meprobamate } \\
\text { Placebo } \\
\text { Meprobamate } \\
\text { Placebo } \\
\text { Meprobamate } \\
\text { Placebo } \\
\text { Meprobamate } \\
\text { Placebo } \\
\text { Meprobamate } \\
\text { Placebo } \\
\text { Meprobamate } \\
\text { Placebo } \\
\text { Meprobamate } \\
\text { Placebo }\end{array}$ & $\begin{array}{r}2 \\
1 \\
6 \\
2 \\
1 \\
2 \\
1 \\
1 \\
-1 \\
2 \\
\end{array}$ & $\begin{array}{r}13 \\
7 \\
7 \\
8 \\
6 \\
9 \\
9 \\
7 \\
4 \\
4 \\
5 \\
1 \\
3 \\
3\end{array}$ & $\begin{array}{r}2 \\
11 \\
4 \\
8 \\
6 \\
6 \\
6 \\
3 \\
5 \\
3 \\
4 \\
6 \\
6 \\
8 \\
12\end{array}$ & $\begin{array}{l}- \\
- \\
\frac{1}{1} \\
\frac{-}{-} \\
\frac{2}{1}\end{array}$ & $\begin{array}{l}E \\
= \\
= \\
E \\
= \\
E \\
-\end{array}$ & $\begin{array}{r}- \\
- \\
1 \\
3 \\
3 \\
3 \\
6 \\
9 \\
11 \\
5 \\
10 \\
4 \\
3\end{array}$ \\
\hline
\end{tabular}

patients improved subjectively and objectively. The two groups were compared statistically by comparing the proportions improved in each. For these comparisons arc sine transformation of the square roots of the proportions (to achieve normality of distribution) were employed and the critical ratios (C.R.) calculated (Davies, 1954). The probability levels (P) of these critical ratios were then noted. In some instances $\chi^{2}$ tests, using Yates' correction, were also used, the two methods, as expected, showing general agreement. In Table III the incidence of improvement as assessed by the doctor was not significantly greater in the " meprobamate group" $(P>0.05)$, although this group tended to do better. In this comparison, for statistical purposes, the patients were considered to be either improved or unimproved and a one-tail test used. The self-rating of the 36 patients showed significantly better response with meprobamate $(\mathrm{C} . \mathrm{R} .=1.98 ; 0.02<\mathrm{P}<0.05)$. If the other four patients are taken into account the difference is not significant.

Table IV shows that all symptoms tend to improve during the trial and with one exception those receiving meprobamate have a greater tendency to improve. The exception is the symptom of depression, where the greater number of patients improved with placebo. Anxiety, phobic-compulsive phenomena, and perhaps feelings of tension are improved in the meprobamate group to a statistically significant greater degree. Anxiety in those 36 completing the trial showed a highly significant improvement with meprobamate, 15 out of 17 improving with meprobamate and only eight out of 19 with placebo
$(C . R .=3 ; P<0.01)$. Even if the other four of the total series, including the three on meprobamate admitted to hospital unimproved, are taken into account the improvement is still significant (C.R. = $2.29 ; 0.01<\mathbf{P}<0.025)$. The number of patients whose symptoms of tension improved to the rating of " much better" was significantly greater with meprobamate in those completing the trial (C.R. = $1.74 ; 0.01<\mathrm{P}<0.05$ ), but just fails to reach this level if those admitted to hospital are taken into account as unimproved (C.R. $=1.6 ; \mathrm{P}>0.05$ ). The phobic and compulsive group of symptoms was improved in a greater proportion of patients with meprobamate (C.R. $=2.01 ; 0.01<P<0.05)$ and it still reaches the $5 \%$ level of significance if all 40 patients are considered (C.R. $=1 \cdot 86$; one-tail test; $0.01<\mathbf{P}<0.05)$. Sleep, appetite, somatic pains, which include headaches and depression, did not show any significant degree of difference between the two groups.

The side-effect most often noticed by the patient was drowsiness, nine of the 20 patients receiving $400 \mathrm{mg}$. meprobamate q.d.s. felt drowsy for periods from two days up to two weeks, by which time the effect had worn off. One patient receiving placebo complained of the same thing for a few days. This difference between the two groups is significant $\left(\chi^{2}=6.5 ;\right.$ d.f. $\left.=1 ; P<0.02\right)$. One patient on meprobamate complained of a dry throat and aching legs in addition to his many somatic symptoms. One patient with similar somatic symptoms felt shivery and defaecated more frequently after taking the placebo tablets. None of the more serious 
toxic effects which have been reported with meprobamate occurred in these 20 patients.

\section{Discussion}

The general or overall assessment in these patients showed no significantly greater degree of improvement in those receiving meprobamate compared with those receiving placebo. The exception to this is the result of the self-rating by the 36 patients who completed the trial. One hesitates to ascribe too much importance to this finding, as, discounting three patients receiving meprobamate and yet requiring admission to hospital for psychiatric symptoms, it would favour the result of this medication. This part of the result of the trial is in accord with the findings of Raymond et al. (1957). However, their paper, based on the patients' subjective estimate of the effect of the tablets (very good, good, none, poor, or very poor) did not bring out another aspect shown in the present study, that certain symptoms are improved. Anxiety has been alleviated to a significant degree, in agreement with many papers, including the trial described by West and Fernandes da Fonseca (1956). Similarly, the feeling of tension is decreased in these patients as described frequently in other reports (Heller, Walton, and Black, 1957). As the phobic-compulsive disorders do not usually respond readily to treatment, any drug which relieves distress in these conditions is worthy of note. When considering the individuals in the group with these symptoms, those improving were those with fears of travelling, of crowds, of being shut in, or ceasing to breathe. Of course, not all of these patients improved, but none of the three with compulsions, e.g., checking taps or the contents of a handbag, altered. The symptoms which did improve in this phobiccompulsive group were those most closely related to anxiety. Regarding the symptom of depression, the results indicate that this symptom may do better with placebo than with meprobamate but the difference is not statistically significant. Of those completing four weeks on treatment, one having placebo and one having meprobamate, were rated as becoming more depressed. Two of those patients receiving meprobamate, who were admitted to hospital during the trial, were reported to have become more depressed. Headaches were not improved to a significant degree, contrary to the findings of Selling (1955).

No side-effects seriously affecting the patients' health were noted in this trial. Almost half of the patients taking meprobamate complained of drowsiness during the first two weeks, after which time it disappeared. A controlled trial of hypnotics has shown that meprobamate has a hypnotic effect (Hinton and Marley, to be published). This does not substantiate the claim that it tranquillizes without impairing the alertness of the patient. However, its effect in relieving anxiety, feelings of tension, and the irrational fears in phobic conditions has been shown.

\section{Summary}

A controlled trial treating 40 anxious out-patients with either meprobamate or a placebo for four weeks is described. The general improvement and the change in the individual symptoms were studied.

The general improvement with meprobamate failed to reach a significantly higher level than improvement with the placebo.

There was a significantly greater alleviation of anxiety, feelings of tension, and phobic symptoms with meprobamate. Insomnia, anorexia, somatic symptoms, including headaches, were not significantly improved by meprobamate.

Depression in the placebo group improved further than in the meprobamate group, but not to a statistically significant degree.

Almost half of those receiving meprobamate were drowsy during the first fortnight. No serious toxic effects were noted.

I would like to thank Dr. D. L. Davies, who suggested the design of this trial and whose help has made it possible. My thanks are also due to the consultants of the Maudsley Hospital who have permitted me to treat their patients; to Dr. A. E. Maxwell for his advice on the statistical analysis; to Mr. W. T. Brookes, the pharmacist, for his willing cooperation, and to Lederle Laboratories Division for supplying " miltown" tablets and the placebo.

\section{REFERENCES}

Berger, F. M. (1954). J. Pharmacol., 112, 413.

- Hendley, C. D., Ludwig, B. J., and Lynes, T. E. (1956). Ibid., 116, 337 .

Borrus, J. C. (1955). J. Amer. med. Ass. 157, 1596.

Council on Drugs (1957). Ibid., 164, 1332.

Davies, D. L., and Shepherd, M. (1955). Lancet, 2, 117.

Davies, O. L. (1954). The Design and Analysis of Industrial Experi-

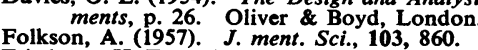

Friedman, H. T., and Marmelzat, W. L. (1956). J. Amer. med. Ass., 162,628 .

Heller, G. C., Walton, D., and Black, D. A. (1957). J. ment. Sci., 103,581 .

Ludwig., B. J., and Piech, E. C. (1951). J. Amer. chem. Soc., 73, 5779. Raymond, M. J., Lucas, C. J., Beesley, M. L., O'Connell, B. A., and Fraser Roherts, J. A. (1957). Brit.med. J., 2, 63.

Selling, L. S. (1955). J. Amer. med. Ass., 157, 1594.

West, E. D., and Fernandes da Fonseca, A. (1956). Brit. med. J., 2, 